\title{
An atypical form of mucolipidosis III
}

\author{
P Freisinger, J C Padovani, P Maroteaux
}

\begin{abstract}
We report two sibs showing a very mild form of mucolipidosis III with no clinical signs but isolated involvement of the hip and very mild abnormalities of the spine. This indicates that a storage disease, in particular mucolipidosis III, should be considered in any case of isolated bilateral hip dysplasia.

The differences from other reported atypical variants of mucolipidosis III are discussed.

( 7 Med Genet 1992;29:834-6)
\end{abstract}

Mucolipidosis III is a well delineated disorder but its clinical variability is still underestimated. The typical form is relatively easy to recognise, but the diagnosis of clinical variants can be difficult. We report here the observations on two sibs in whom only the radiological abnormalities of the hip allowed the diagnosis of mucolipidosis III to be made.

\section{Case reports}

CASE 1

Case 1, a 7 year old girl (fig 1), was referred to the outpatient clinic for isolated limping without pain, with onset a few weeks before consultation. There were no abnormalities in the past medical history. She is the second of three children of normal, non-consanguineous parents. Her older brother, 10 years old, was normal. Her younger brother, $4 \frac{1}{2}$ years old, is also affected by mucolipidosis III, a diagnosis which was made five years after this consultation. The family history was otherwise normal.

Clinical examination showed no anomaly apart from a slightly waddling gait. She is of normal intelligence, doing very well at school.

Radiological examination of the pelvis (fig 2A) showed shallow acetabula with irregular oblique roofs. The femoral epiphyses were unevenly ossified and flattened. There was coxa valga deformity of both femoral necks and subluxation of the right femoral head.

Lateral $x$ rays of the spine (fig $2 \mathrm{C}$ ) showed a slightly ovoid shape of the dorsal vertebral bodies but within normal limits. The rest of the skeletal survey was normal (fig 2E).

Discrete opacifications of the cornea were

Hôpital des Enfants Malades, 149 rue de Sèvres, 75743 Paris Cedex 15, France. P Freisinger J C Padovani

P Maroteaux

Correspondence to Dr Maroteaux.

Received 4 January 1992. Revised version accepted 10 April 1992. found on slit lamp examination. The bone marrow showed large, vacuolated plasmocytes, and the peripheral blood film was normal. Urinary excretion of acid mucopolysaccharides and the activity of several hydrolases in leucocytes were normal, whereas their serum levels were considerably raised (table).

On account of these results the diagnosis of mucolipidosis III was established. Cardiac

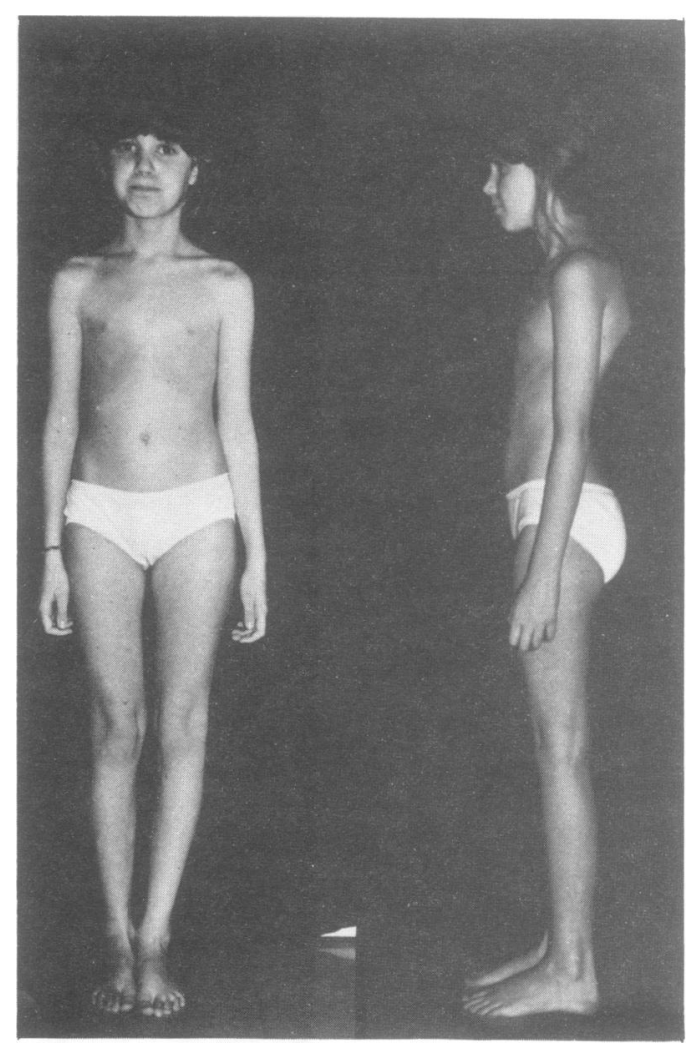

Figure 1 Case 1 at the age of 10 years.

sonography was normal and the patient underwent bilateral triple pelvic osteotomy one year later. She was followed up regularly for five years. Growth development was normal $(159 \mathrm{~cm}$ at 14 years) and clinical examination has remained normal apart from slight muscular insufficiency of the pelvic girdle since the operation.

CASE 2

Case 2 is the younger brother of the first patient. He presented to the outpatient clinic at the age of $9 \frac{1}{2}$ years with difficulty in walking, accompanied by pains in the knees at the end of the day.

Apart from a cleft palate there was no abnormality in his past medical history. Clinical examination showed a patient of normal height $(137 \mathrm{~cm})$ with a slightly stiff, waddling gait. There was a discrete left paravertebral lumbar gibbous. No restriction of joint mobility could be found apart from moderate limitation of abduction and external rotation of the hip. The rest of the examination was normal.

$X$ rays of the pelvis (fig 2B) showed an oblique acetabular roof with irregular contours. The femoral heads were flattened and irregular and there was bilateral coxa valga but no subluxation. Lateral $x$ rays of the spine (fig 

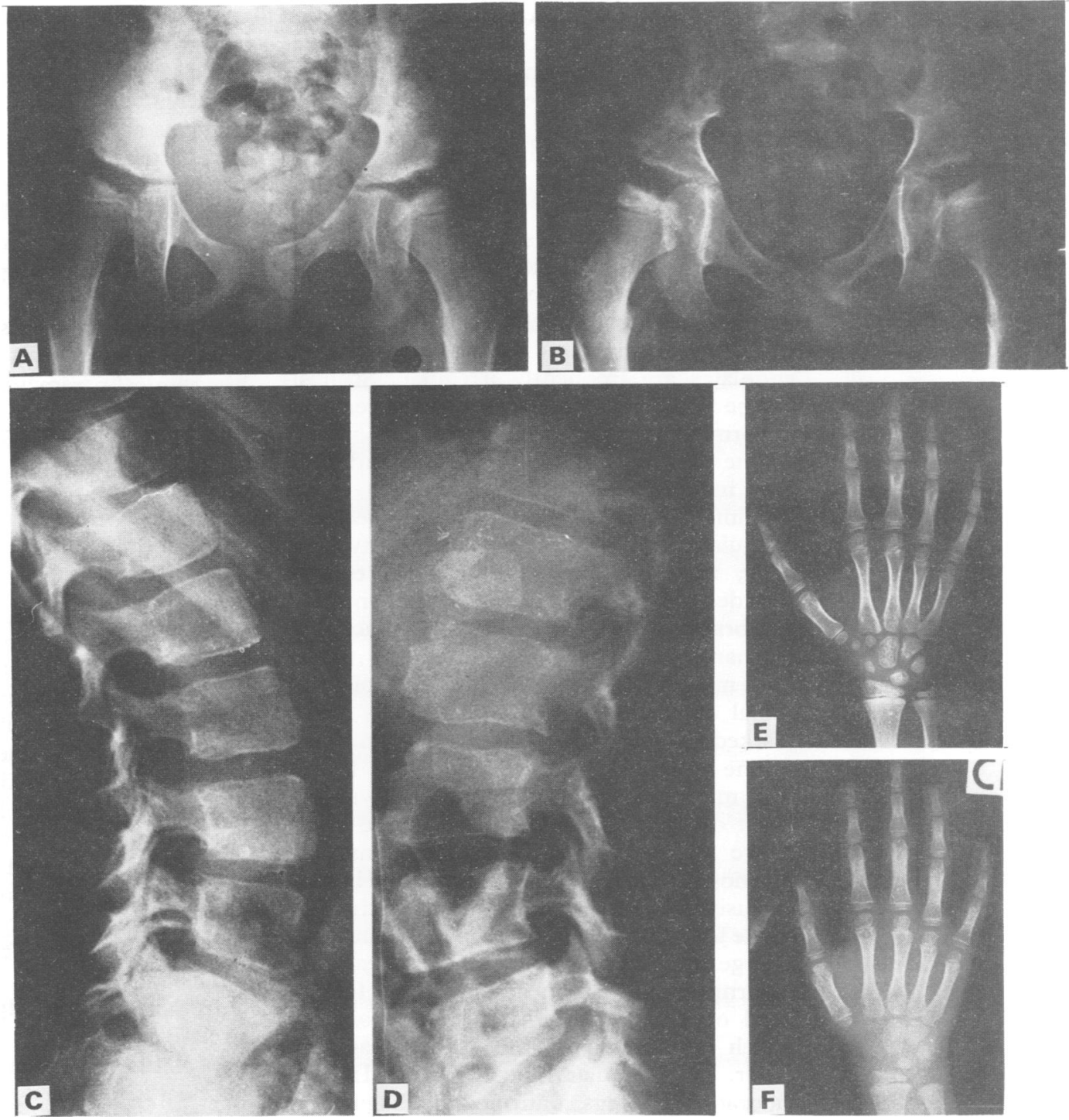

Figure $2(A)$ Pelvis of case 1 at the age of 7 years. Note the flattened femoral head, the broad femoral neck, and coxa valga deformity. (B) Pelvis of case 2. The lesions are very similar to those of case 1. (C) Lumbar spine of case 1 at the age of 7 years. Besides a slightly ovoid shape of D12 the image is strictly normal. (D) Lumbar spine of case 2. Note the protrusion of the central part of the vertebral bodies, a slight reduction of the posterior part of the vertebral body, and the central depression of $L 1-L 4$. (E) Hand of case 1 showing no anomaly. (F) Hand of case 2 showing no anomaly.

Serum assays of lysosomal enzymes

\begin{tabular}{lrrc}
\hline & Case 1 & Case 2 & Controls \\
\hline $\begin{array}{l}\text { Hexosaminidase A } \\
\text { Hexosaminidase A + B }\end{array}$ & $5 \cdot 900$ & $2 \cdot 581$ & $550-150$ \\
$\begin{array}{l}\text { Arysulphatase A } \\
\text {-glucosaminidase }\end{array}$ & 210 & 230 & $2-8$ \\
$\begin{array}{l}\text { Arysulphatase B } \\
\beta \text {-glucuronidase }\end{array}$ & 110 & 129 & $10-50$ \\
$\begin{array}{l}\alpha \text {-fucosidase } \\
\alpha \text {-mannosidase }\end{array}$ & 120 & 158 & $3-10$ \\
$\beta$-mannosidase & $1 \cdot 877$ & $1 \cdot 680$ & $100-830$ \\
& $2 \cdot 360$ & 1.284 & $10-20$ \\
& 860 & & $180-600$ \\
\hline
\end{tabular}

2D) showed moderate protrusion of the central part of the vertebral bodies in the lumbar spine and a slight reduction of the posterior portion of the lower dorsal vertebral bodies, which were slightly irregular with a discrete central depression. The rest of the radiological examination was normal (fig $2 \mathrm{~F}$ ).

On account of the family history mucolipidosis III was suspected. The diagnosis was confirmed by the raised multiple lysosomal enzymes in the patients' serum (table).

\section{Discussion}

Mucolipidosis III, first described in 1966 as pseudopolydystrophy by Maroteaux and Lamy, ${ }^{1}$ is an autosomal recessively inherited lysosomal storage disease resulting from deficiency of the enzyme UDP-N-acetylglucosamine, lysosomal protein precursor $\mathrm{N}$-acetylglucosamine 1-phosphotransferase. ${ }^{23}$ The typical form of mucolipidosis III is characterised by short stature, mild facial dysmorphism, flexion deformity of the fingers, and limited joint mobility. Mild mental retardation is frequent. Corneal opacities can be seen on slit lamp examination. The first symptoms usually appear at 2 to 4 years of age and progress slowly. At the end of the second decade the condition seems to stabilise.

Radiological examination shows typical abnormalities including a combination of severe 
pelvic and unusual vertebral changes which are thought to be specific for mucolipidosis III, as well as abnormalities of the tubular bones. These signs have also been reported as 'dysostosis multiplex'. ${ }^{4}$ The changes in the pelvis consist of flaring of the iliac wings, constriction of the iliac bodies, and oblique acetabular roofs.

The vertebral bodies are moderately flattened and present a roughly ovoid contour with underdevelopment of their posterior parts in the dorsal spine and hypoplasia of their anterior third in the lumbar spine. Their endplates are frequently irregular. Scoliosis can be found as a consequence of the vertebral abnormalities.

The tubular bones are shortened and wide. The most striking changes are seen in the proximal femur with a small, flattened, and irregular epiphysis, coxa valga deformity of the neck, and subluxation. Bone age can be retarded. The clinical diagnosis is confirmed by normal urinary excretion of acid mucopolysaccharides, vacuolated plasmocytes in the bone marrow, normal activity of multiple lysosomal enzymes in white blood cells and a marked rise of these enzymes in serum. ${ }^{15}$

The patients described here suffer from a very mild form of mucolipidosis III with late onset of walking difficulties and none of the above mentioned typical clinical signs. The diagnostic clue for mucolipidosis III came exclusively from the radiological investigations of the hip. The dysplastic proximal femur with a large neck and a flattened head, coxa valga deformity, and subluxation of the femoral head on one side were the only anomalies, which raised the possibility of a storage disorder, in particular mucolipidosis III. The laboratory findings confirmed the diagnosis of the latter. This underlines the importance of biochemical investigations in the diagnosis of mucolipidosis III as has already been pointed out by Kelly et al. ${ }^{5}$ Atypical forms of mucolipidosis illustrating the clinical variability have been previously documented. Lamy and Maroteaux ${ }^{6}$ reported two brothers with a peculiar form of spondyloepiphyseal dysplasia. These patients did not present the features of the typical form of mucolipidosis III, particularly on clinical examination, described by the same authors. ${ }^{1}$ Several years later biochemical investigations led to the diagnosis of mucolipidosis III.

Kelly et $a l^{5}$ reported several cases with moderate clinical signs and the radiological evaluation of one of these patients (no 5) by Melhem et $a l^{7}$, showed particularly mild but generalised abnormalities.

A distinction of classical, mild, and severe forms of mucolipidosis III has been proposed. ${ }^{8}$ Patients with the mild form have normal intelligence, no pronounced facial dysmorphism, normal hands and mild dysostosis multiplex. However, reviewing published reports, we could not find another cause of biochemically proven mucolipidosis III without typical clinical signs and isolated involvement of the hip. The clinical variability could be explained by the genetic heterogeneity of mucolipidosis III, which was illustrated by complementation studies showing the existence of three genetically distinct subgroups. ${ }^{9}$ This heterogeneity has been confirmed by showing that the mutant enzymes in distinct complementation groups differed from each other by different biochemical parameters. ${ }^{10}$ However, no correlation could be established between genetic heterogeneity and clinical phenotype.

There is also variability in the expression of the same genotype, as the differences in the changes in our two patients and in two affected sibs reported by Melhem et $a l^{7}$ show. This wide phenotypic variability is well known in other lysosomal storage diseases. For example, in mucopolysaccharidosis I, clinical and radiological data of Hurler's disease are very different from the Scheie type. In the latter, the evolution is compatible with long survival without severe disorder of skeletal growth.

The cases reported here of biochemically proven mucolipidosis III without typical clinical signs and few radiological features indicate that mild forms could be missed. It is important to avoid confusion with other disorders which have a better prognosis and do not require the same clinical surveillance as mucolipidosis III.

In the case of hip dysplasia with coxa valga, a relatively large neck, flattening, and subluxation of the femoral head, simple screening is necessary in order to eliminate mucolipidosis III, either by slit lamp examination or by assay of serum hexosaminidase or other hydrolases.

1 Maroteaux P, Lamy M. La pseudo-polydystrophie de Hurler. Presse Med 1966;74:2889-92.

2 Waheed A, Hasilik A, Cantz A, Von Figura K. Marked deficiency of $\mathrm{N}$-acetylglucosamine-1-phosphotransferase in fibroblasts of patients with mucolipidosis III. Hoppein fibroblasts of patients with mucolipido
Seyler's $Z$ Physiol Chem 1982;363:169-78.

3 Reitman ML, Kornfeld S. Lysosomal enzyme targeting. $\mathcal{f}$ Biol Chem 1982;256:11977-80.

4 Spranger JW, Wiedemann HR. The genetic mucolipidoses Humangenetik 1970;9:113-39.

5 Kelly TE, Thomas GH, Taylor HA, et al. Mucolipidosis III (pseudo-Hurler polydystrophy): clinical and laboratory studies in a series of 12 patients. fohns Hopkins Med $f$ 1975;137:156-75.

6 Lamy M, Maroteaux P. Dysplasie spondyloépiphysaire atypique observée chez deux frères. Arch Fr Pediatr 1957;14:506-10.

7 Melhem R, Dorst JP, Scott CI, McKusick VA. Roentgen findings in mucolipidosis III (pseudo-Hurler polydystrofindings in mucolipidosis III (pseu
phy). Radiology 1973;106:153-60.

8 Gehler J, Sewell AC, Spranger J. Clinical variability in mucolipidosis III. Clin Genet 1981;9:504.

9 Honey NK, Mueller OT, Little LE, Miller AL, Shows TB. Mucolipidosis III is genetically heterogeneous. Proc Nat Acad Sci USA 1982;79:7420-24.

10 Little LE, Mueller OT, Honey NK, Shows TB, Miller AL. Heterogeneity of N-acetylglucosamine 1-phosphotransferase within mucolipidosis III. $\mathcal{f}$. Biol Chem 1986;261:733-8. 